\title{
The Role of Sensitivity Training for Managing Diversities in Sustainable Smart Societies
}

\author{
By Ceren Karaatmaca ${ }^{1}$, Fahriye Altinay ${ }^{2}$, Zehra Altinay $^{2}$, Gokmen Dagli ${ }^{1}$
}

\begin{abstract}
Entrepreneurial attempts play a key role to make behaviors in a global connected context. In this attempt, it is crucial to manage diversities and extend the capacity of the understanding and knowledge on the sensitivity for making sustainable and smart societies. This research aims to evaluate the perceptions of members of Non-Government Organizations (NGOs) on sensitivity training and sheds a light on description, content and benefits on sensitivity and its' training in order to create mutual understanding from life experiences on different types of NGOs. As qualitative research was employed in this research, interview and word association methods were used as data collection methods. As the study group, 35 members of various NGOs participated the research and their reflections on sensitivity training as a managerial and organizational perspective were analyzed using interview and word association methods coding through content analysis. In this respect, for data analysis, computer-aided qualitative data analysis software (RQDA) was conducted that $\mathrm{R}$ package was used. This research revealed firstly that the most frequently mentioned words for sensitivity definition were empathy which is related with interpersonal relationships and emotional intelligence (EQ); self-knowledge which is related with awareness and conscious; and the viewpoints of oneself like perception and bias. Secondly, to examine the suggestions of the different NGO participants suggesting the managers for raising awareness on sensitivity among their employers in a workplace, themes were identified as managers' own personal approach that is being their own example, trainings and the approach of the buman resources department. Thirdly, the benefits of an education for sensitivity skill to sustainable smart societies for global citizenship and its contribution to the development of the sustainable smart societies are overlooked. The main themes were collected under the headings of communication, productivity and respected organization. In the light of the findings it can be stated that with sensitivity training in the workplace, social relations and group atmosphere improve and at the referred point, when benefits of sensitivity training is overlooked,very useful results are reached for individuals, groups and organizations that are directly related for sustainable and smart societies. The sensitivity training is an activity to determine the tasks to be carried out in order to achieve certain goals, to determine the personnel to perform this function, to determine the competencies and responsibilities and organizational relations of global citizens in smart societies.
\end{abstract}

Keywords: Empathy, Global Citizenship, Management Sensitivity, Smart Society, Training

\section{Introduction}

Management relies on understanding functions of an institution, understanding of the roles and the voices on partners, understanding on the of quality institutions and human and material resources to maintain the quality, information technology shapes these implications (Ozansoy, Altınay, Altınay, 2018, Aksal, A, 2015).

Factors of refugee crisis, the silk road, climate change, aging population, smart services

| ${ }^{1}$ Faculty of Education, University of Kyrenia Şehit Yahya Bakır Sokak Karakum Kyrenia TRNC Mersin 10Turkey

${ }^{2}$ Graduate School of Educational Sciences, Societal Research and Development, Faculty of Education, Near East University, Near East Boulevard, ZIP: 99138 Nicosia TRNC Mersin 10 - Turkey 
and informal economy, global economy make a significant evidence to realize the entrepreneurship that has become essential activity within the different spheres of the economy and society (Altınay, Altinay, 2018). Entrepreneurial behaviors are important for management, information technology, health, education. This puts an emphasis to understand the culture of each institution to proceed competitive advantage and reputation. The competitive advantage and reputation require agile actions to adapt changes. In this respect, balancing the focus of 'what is' in the present and 'what should be' in the future show the tendency to analyze studies on sensitivity (Altınay, Dagli, Altınay,2018; Hutnik, Gregory, 2008).

Changing economy and social patterns sheds a light to understand the changing organizations to be a learning organization. Entrepreneurship becomes an important attempt to act agile management in fostering global and collective ways (Akcil, Altınay, Altinay, Dagli, Altinay, 2018: Sozudogru, Altinay, Dagli, Altinay \& Altinay , 2019). There are new research avenues. These research avenues guide us to shape the framework to understand interdisciplinary perspectives on sensitivity for creating collective understanding for entrepreneurship and sustainability for the welfare of the society. Following factors affect the way of life in shaping global citizenship within diversity (Poteat, Park, Solares et al., 2017; Denes, 1975).

- The well-being and quality of life of refugees

- Healthcare management of refugees: identifying signs of exploitation

- Legal and societal discrimination against immigrants and refugees

- The role of service industries in the social and economic integration of refugees

- Assessing modern slavery and human exploitation risks

- Labor exploitation in service industries' value chains

- The role of the informal sector in the sharing economy

- Policy initiatives to tackle the informal economy in the service sector

- How innovation in the service industries can facilitate the growth of ago-ecological farming and food production for human and societal health and wellbeing.

- Evaluating the responsibilities of marketing in framing/promoting ecological messages to enhance consumption of foods that advance ecological and human health and wellbeing.

- Evaluating the interrelationship between food, health, sustainability and consumer and societal well-being.

- Assessing the acceptance of novel food innovations in addressing food insecurity due to climate change

- Smart transformations: innovation, creativity and business models for smart services

- Societal, cultural and economic impacts of smart services

- One Belt and Road Initiative for international and domestic service industry issues.

- The economic, political, environmental, and social cultural impacts of the service industry development on the Silk Road area.

The indicated research avenues emphasis on the importance of sensitivity related studies. Sensitivity becomes crucial factor in the world in order to make global connected societies within a mutual context (Gazi A, 2016; Kajee, 2018). It requires a kind of 
training to increase everyone's awareness of his or her own feelings and the feelings of others and to enhance interpersonal relations through the exploration of the behaviour, needs, and responses of the individuals making up the group. Therefore, sensitivity training creates a bridge among people to make knowledge and understanding (Altinay, Dagli, Altinay, 2017; Back, 1973).

To effectively work and communicate with everyone in workplace, considering diversities and understanding differences in a whole manner is crucial. In this respect, as women may have broken the ivory ceiling, but they are still fighting for old-fashioned discrimination. Women are now claiming to take place in the public sphere and have satisfying work in the professions that would gain them authority, prestige, power and salary that any professional work commands. However, Timmermans and Jourova (2017) argue that when we look at women in the public domain, we see that their role has been subordinate to men. We witness male doctors, female nurses: male executives, female secretaries; male principals, female teachers, which also create huge gender pay gap between these professions (Williams, 2005). This is an example to show how sensitivity is important for managing diversity within life experiences.

On the other hand, for the classification of NGOs that are the main dimensions of this study; as per the World Bank Typology, they can be classified into Operational and Advocacy NGOs. In Operational NGO, the main purpose is to design and implement the development-related projects. The scope of the Operational NGOs can be national, international or even community based. Diversely, the main purpose of an Advocacy $\mathrm{NGO}$ is to promote a specific cause. It makes efforts to raise awareness and knowledge by doing various activities like lobbying, press work and activist events (Fox,2000). NGOs exist for a variety of purposes, usually to further the political or social goals of their members. Examples include improving the state of the natural environment, encouraging the observance of human rights, improving the welfare of the disadvantaged, or representing a corporate agenda. However, there are a huge number of such organizations and their goals cover a broad range of political and philosophical positions.

When the literature about classification of NGOs is examined, it can be recognized that each country has different type of perspective of classifying the NGOs. The concept of these organizations is very broad (Fox, 2000). In Turkey and Northern Cyprus NGOs vary by entities called as cooperatives, trade unions, associations and foundations (Hirai, 2007). These can also be classified as NGOs related with trade that is representatives of private sector and all others that are not trade related. Although this classification is not observed much in Western Countries, there are studies comparing trade unions and NGOs keeping them separately. The studies explore issues arising in relations between trade unions and non-governmental organizations (NGOs). These relations have a long history and are complex, ranging from close co-operation to problematic relationships. When unions and NGOs co-operate, their joint impact on social and political events can be quite powerful. When such co-operation fails, it can significantly set back the agenda of both. Consequently, success or failure in union/NGO co-operation will affect the direction and the pace of social development or, in general terms, what world society will look like in the coming decades (Fox,2000).

Both unions and NGOs are civil society actors. What they have in common are specific 
agendas for the improvement of society. Trade unions have always held that a consistent defense of the interests of their members over the long term required them to work on issues (including political and social democracy, civil and democratic rights, poverty elimination, equality, and the rule of law) influencing the well-being of people and society as a whole. They could thus legitimately claim to be serving the interests of society in general, as could NGOs acting on the desire to advance and improve the human condition (Gallin,2001).

The aim of this research is therefore to evaluate perceptions on sensitivity in working experiences of Non-Government Organizations taking of trade union and non-trade union perspective and the different perspective gender basis. Therefore, following research questions are answered;

1. What are first five words that the participants recall for the term sensitivity?

2. What does the participants suggest the managers to do in order to raise awareness on sensitivity among their employers in a workplace?

3. What would be the benefits of an education for sensitivity skill to sustainable smart societies and its contribution to the development of the sustainable smart societies.

\section{Methodology}

\subsection{Research Design}

In this research study, sensitivity training was done for examining the context of sustainable and smart society through the life experiences of research participants. In this respect, qualitative research design was conducted by focusing on perceptions and experiences of researchers and participants from the reflections of cases in different situations (Simsek and Simsek, 2016; Yin, 1994).

\subsection{Study Group}

The study group consists of 35 members from Non-Government Organizations. These organizations include different types of NGOs: Disabled Association NGOs, Profession NGOs, Charitable Institutions, Vocation and Art Organizations. This sampling method is called maximum diversity sampling of the types of purposeful sampling methods (Simsek and Simsek, 2016). The aim of maximum diversity sampling is to create a relatively small sample and to reflect the maximum diversity of individuals who can sample the side studied. In this type of sampling, the purpose is not to generalize, but rather to try to find out if there are any common or shared phenomena between varying situations and to reveal the different dimensions of the problem according to this diversity (Patton,1987, Akt. Simsek \&Simsek,2016). In this respect different perspectives from 2 different types of NGOs, Trade Unions versus Non-Trade Union NGOs are gathered in order to evaluate perceptions on sensitivity in working experiences with also different gender point of views. 
Table 1 : Study Group

\begin{tabular}{llcc}
\hline & Participant & $\mathrm{N}$ & $\%$ \\
\hline Education level & Graduate & 10 & 30 \\
\multirow{3}{*}{ Type of NGO } & Undergraduate & 25 & 70 \\
& Disabled Association & 11 & 32 \\
& Profession NGOs & 12 & 34 \\
Trade Perspective & Charitable Institutions & 6 & 17 \\
& Vocation and Art Organizations & 6 & 17 \\
& Trade Union NGO & 12 & 34 \\
Gender & Non-Trade Union NGO & 23 & 66 \\
& Female & 22 & 63 \\
Age & Male & 13 & 37 \\
& $22-40$ & 12 & 34 \\
TOTAL & $40-55$ & 15 & 42 \\
& $55<$ & 8 & 24 \\
& & $\mathbf{3 5}$ & 100 \\
\hline
\end{tabular}

\subsection{Data Collection Tools and Analysis}

To examine perceptions of research participants on sensitivity training and making the understanding on their life experiences, interview questions were asked to research participants as data collection method (Simsek and Simsek, 2016). In this research also the word association method is used for the participants recalling for the term sensitivity. Word association is considered one of the most effective techniques in market research, with a widely spread use, which is possibly due to the ease of application compared to other techniques. Because of these characteristics, its use in qualitative studies is quite frequent (Ares \& Deliza, 2018).

In the study, the views of research participants on describing a situation that requires sensitivity, their suggestions for the managers for raising awareness on sensitivity among their employers in a workplace, and the benefits of an education for sustainable smart societies and its contribution to the development of the sustainable smart societies were collected as data. These reflections were analyzed based on content analysis method.

\subsubsection{Content Analysis Phase}

Regarding to the aim of the research study, reflections of participants were categorized forms from the interviews were examined and analyzed by content analysis. The main purpose in content analysis is to reach the concepts and relations that can explain the collected data. The data summarized and interpreted in descriptive analysis are subjected to a deeper process in the content. The concepts and themes that are not noticeable with a descriptive approach can be discovered as a result of this analysis. For this purpose, the steps like, firstly conceptualizing the collected data, then organizing them according to the emerging concepts in a logical manner and determining the themes that explain the data accordingly are followed (Yildirim and Simsek, 2016). As Strauss and Corbin (1990) stated, "Science cannot exist without concepts; concepts help us understand facts and think effectively on them. When we name concept; we can ask questions about that concept, we can analyze that concept and relate it to ar other concepts". The basic process in content analysis is to bring together similar data in the 
framework of certain concepts and themes and to interpret them by organizing them in a way that the reader can understand. As a result of examining the concepts, their relations with each other are revealed and these relations are explained with a higher-level theme. It is more abstract and general than the concepts obtained in category or theme content analysis. The themes and codes by "content analysis" was implemented (Simsek and Simsek , 2006).

\subsubsection{Category Development Phase}

Computer-aided qualitative data analysis software (RQDA) was conducted that $\mathrm{R}$ package was used while making the creation of category.

\subsubsection{Validity and Reliability}

Validity and reliability of the research play a great role. The reliability of the research was done based on Miles and Huberman's (1994) formula (Consensus / Consensus Difference). The level of reliability is was indicated based on harmony/consensus between expert and researcher evaluations that was is $90 \%$ or higher (Saban, 2009).

\subsubsection{The role of the researchers}

Researchers become flexible by following inductive process in order to internalize patterns. They made re-analysis of participant reflections for making holistic understanding (Simsek and Simsek, 2016).

\section{Results}

As for the results of the study common codes collected with word association technique, the suggestions for the managers for raising awareness on sensitivity among their employers in a workplace, and the benefits of an education for sustainable smart societies and its contribution to the development of the sustainable smart societies were determined.

\subsection{Word Association Term Sensitivity}

In this section codes collected with word association technique is put under the scope. Valid responses from participants were considered for data analysis (i.e. responses corresponding to strings of characters with-out sense were not considered). Frequency of mention of each word was calculated. Then, data was analyzed using content analysis: terms with similar meaning were grouped into categories using inductive coding by triangulation (Guerrero et al., 2010). 


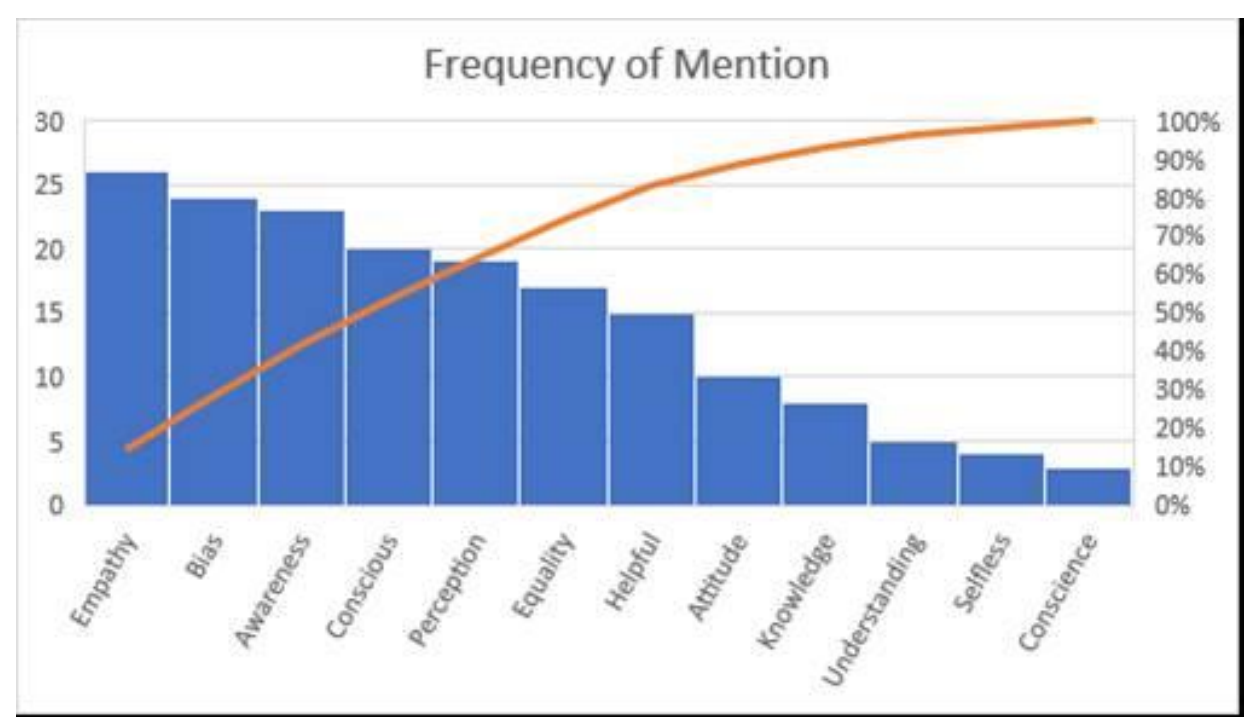

Fig. 1: Frequency of mention of the most frequently mentioned individual words when participants were asked to write down the first five words, terms or phrases that came to their minds when thinking of sensitivity training.

Frequency of mention of words, categories and dimensions were calculated without considering if words were provided by the same participant or by different participants (Guerrero et al., 2010).

A total of 34 different words were mentioned when participants were asked to write the first 5 words, terms, phrases that came to their mind when they thought of sensitivity training. Most of the responses consisted of individual words. As shown in Fig. 1, the most frequently mentioned word was empathy related with interpersonal relationships. Most of the remaining most frequently mentioned words were related to self knowledge of a person like awareness and conscious. Other frequently mentioned words were related to the viewpoint of oneself like perception and bias.

\subsection{Suggestions for Managers for Raising Awareness on Sensitivity in Workplace}

In this section the concern is to examine the suggestions of the different NGO participants suggesting the managers for raising awareness on sensitivity among their employers in a workplace. As mention in Study group details thirty-five participants were interviewed during the study, 13 of whom $(37 \%)$ were males, and22 of whom $(63 \%)$ were females. The average time of interviews was about 15 minutes. The mean age of the participants was 44 years Three themes and sixteen sub-themes in relation to suggestions for managers for raising awareness were identified (Table 2) from interviews. The main themes were collected under the headings of, managers' own personal approach that is being their own example, trainings and the approach of the human resources department. 
Table 2: Themes and sub-themes outlined in relation for suggestions for managers to increase awareness on sensitivity in workplace among employers

\begin{tabular}{|l|l|}
\hline Theme & Sub-theme \\
\hline $\begin{array}{l}\text { Managers' Own Personal Approach } \\
\text { being their own example) }\end{array}$ & $\begin{array}{l}\text { Increasing the number of people working in different } \\
\text { genders in different age groups and culture. } \\
\text { Having trained in human relations, psychology and } \\
\text { sensitivity. } \\
\text { Being a good listener }\end{array}$ \\
\hline Trainings & $\begin{array}{l}\text { Seminars and Workshops } \\
\text { Conferences } \\
\text { Sensitivity Training } \\
\text { Interpersonal Communication Skills Training } \\
\text { Different Departments giving trainings to each other }\end{array}$ \\
\hline $\begin{array}{l}\text { Approach of the human resources } \\
\text { department }\end{array}$ & $\begin{array}{l}\text { Arranging Sensitivity Training } \\
\text { Arranging Mentoring Programs } \\
\text { Posters and announcements around the sensitivity subject } \\
\text { Team Building activities } \\
\text { Hiring an organizational psychologist } \\
\text { Arranging informative meetings } \\
\text { Arranging aid trips to different organizations and NGOs }\end{array}$ \\
\hline
\end{tabular}

\subsubsection{Managers' Personal Approach}

Managers' own personal approach that is being their own example was found to be a recurring theme in the interviews, and it was considered to be a fundamental requirement and a basic aspect of success in a management position. Some comments that were made included: "First of all, the managers in the workplace must have sufficient sensitivity himself or herself. Otherwise, he will not be able to persuade his her employees to talk about it as much as he she wants." participant no. 2(P2); " I think communication skills are very important, but the majority of the managers unfortunately lack them even in NGOs like this " (P14, P8). According to the participants managerial approach should focus on increasing the number of people working in different genders in different age groups and culture, having trained in human relations, psychology and sensitivity and very importantly being a good listener as a manager.

\subsubsection{Trainings}

Training is one of the most important awareness increasing techniques for employers on sensitivity as well as all parallel subjects as was identified by all participants and has been suggested as one of the requirements for an environment that respects differences and a key for a successful administration. Some comments were as follows: "Activities should be organized so that employees can better understand and boil with sensitivity training." (P11); "Informative intersections can be made during business hours or outside. Different posters can be prepared for awareness." (P6). Most participants suggested trainings are essential at the referred point. The suggested activities on this matter included seminars, workshops, conferences, sensitivity training, interpersonal communication skills training, different departments giving trainings to each other This sentiment was echoed among almost all NGO members and managers. 


\subsubsection{Approach of the Human Resources Department}

In this matter, another approach of the human resources department was identified as a significant theme throughout. The human resources departments' role comes out to be arranging sensitivity training and mentoring programs, preparing posters and announcements around the sensitivity subject, team building activities, hiring an organizational psychologist, arranging informative meetings and arranging aid trips to different organizations and NGOs. Many mentioned that human resources department should be aware of sensitivity $\mathrm{c}$ issues and have enough knowledge in all aspects of the institution to be able to provide effective human resource management input. In this regard, one of the participants commented: "I think HR can appoint experienced people who can help newcomers and more inexperienced employees. This department should also focus on how to deal with communication problems with a little respect and empathy." (P16)

\subsection{Benefits and Contribution to the Development of Sustainable Smart Societies with Sensitivity Training}

At this referred point, the benefits of an education for sensitivity skill to sustainable smart societies and its contribution to the development of the sustainable smart societies are overlooked. Three themes and nine sub-themes in relation to this subject matter were identified (Table 3) from interviews. The main themes were collected under the headings of communication, productivity and respected organization.

Table 3 Themes and sub-themes outlined in relation for outlining the benefits and contribution to the development of sustainable smart societies with sensitivity training

\begin{tabular}{|l|l|}
\hline Theme & Sub-theme \\
\hline Communication & $\begin{array}{l}\text { Communicating correct skills and solve the problems } \\
\text { Improvement interpersonal relations } \\
\text { Systematic Approach }\end{array}$ \\
\hline $\begin{array}{l}\text { Efficiency and } \\
\text { Productivity }\end{array}$ & $\begin{array}{l}\text { Finishing of jobs and more income in a short time } \\
\text { increase in material and moral productivity } \\
\text { regularity and correct system setup } \\
\text { increased motivation and personal satisfaction }\end{array}$ \\
\hline Respected Organization & $\begin{array}{l}\text { inductive personal satisfaction } \\
\text { the correct reflection of the institution in the environment and the } \\
\text { correct image }\end{array}$ \\
\hline
\end{tabular}

\subsubsection{Communication}

Communication was found to be a recurring theme in the interviews, for benefits and contribution to the development of sustainable smart societies with sensitivity training. Some comments that were made included: "When communication is healthy, even if indirectly, people will understand each other better.." participant no. 9(P9); Employees' receiving sensitivity training ensures their self-awareness and strengthening of human relations and their work increases the respect of the smart society in which they live. " (P29). According to the participants the sensitivity training has a beneficial value on communicating with correct skills and solve the problems, as well as improving interpersonal relations and brings out a systematic approach to smart 
society.

\subsubsection{Efficiency and Productivity}

At the referred point, efficiency and productivity are other recurring themes in the interview for the beneficial side of sensitivity training for smart society. In this respect some comments included: "Employees who develop understanding of each other and differences can ensure their peace of mind, so they can work more efficiently." (P33) and "Thanks to the sensitivity education, the help will increase and the isle will end sooner. In this way, income and productivity will increase. Material and emotional sort of increase will be provided. "(P6)

\subsubsection{Respected Organization}

Also respected organization benefit is another aspect as a result of sensitivity training, as the participants indicated. Some of the comments as follows: "The first of an employee who receives the sensitivity training within his or her organization will increase his respect for the organization. At the same time, the image of the organization will benefit if it is announced outside the training program. The main reason is that the image is very important in an organization. "(P23)

\section{Conclusions and Implications}

In the light of the findings, the mentioned areas are mainly the definition of sensitivity according to different individuals on the workplace, especially in this case the NGOs, both trade oriented and non-trade oriented. Secondly, the ways for managers in these organizations to improve sensitivity within the members of the society are examined. Lastly, the benefits of sensitivity training for smart society are put under scope.

One of the definitions of sensitivity comes out to be "empathy" in this study. Empathy is a person's ability to put himself in someone else's shoes and understand his emotions, thoughts and behaviors (Eagles and Wolitzky,1999). The concept of empathy was first handled in aesthetic and epistemological terms. Aesthetically, self-reflection of the emotions and thoughts of the observer during the perception of objects; Epistemologically, it was used to mean the method of achieving the goals of artists and poets (MacIsaac,1999). With empathy also comes out the term Emotional Intelligence (EQ) that is the capacity to be aware of, control, and express one's emotions, and to handle interpersonal relationships judiciously and empathetically (Giardini and Cayró, 2017). In the mentioned point, in the book Working With Emotional Intelligence, Goleman (2006) applies the emotional intelligence concept to the workplace setting. In this analysis, he argues that the emotionally intelligent worker is skilled in two key areas he presents in his emotional competence framework. These are "personal competence" how we manage ourselves, and "social competence " - how we manage relationships. In this current study in the findings it is also observed that the word "sensitivity" has a great relation with words like empathy, awareness and perception. All the mentioned words combine the mentioned concepts of personal and social competence together with sensitivity. For an individual in an organization, being aware of his weaknesses and 
limited sides is also extremely important. An important part of human self-knowledge is self-confidence. Self-confidence is that an individual is sure of their own values and abilities. In addition, the reliability of the individual is important. For this, the individual exhibits moral behaviors and gives importance to the efforts to gain the trust of the society with his honesty. Another sub-dimension of self-awareness is the awareness of taking responsibility for individual success. It is also an incentive for success that the individual sets individual standards and targets for access and constantly develops them to be perfect and constitutes an important dimension of self-awareness or selfawareness.

In this respect, creative relationships of people give an opportunity on social ability to change and to create social awareness and empathy. People with this skill care about emotional interaction and know how to listen, look at things from the perspective of others, and show their sensitivity in this regard. Making others happy, developing them, rewarding them, understanding different viewpoints, personal and group differences, and even creating a creative environment by harmonizing them, dealing with different trends and showing tolerance are the requirements of social awareness. Also, the people with this talent can easily understand and control the vital social relationships network in a group and people with these skills can influence people by using effective believing tactics. They can build consensus and support using complex strategies and indirect influencing methods. People with social skills also send clear and convincing messages in terms of communication. Thus, they developed their skills of message exchange, mutual understanding and knowledge sharing with other people.

Also as in this study, different types of NGOs are taken into consideration. Co-operation between trade unions and NGOs depends far more on whether they share common objectives, and on issues relating to their methods of operation (legitimacy, transparency, accountability, management). In any event, general statements about union and NGO relations are difficult. Even though unions have far more basic common features than NGOs do, they are by no means a homogenous whole: there are obvious differences due, for example, to political tradition or organizational culture. Co-operation therefore always depends on a specific convergence of objectives and on a compatibility of approach and modus operandi between specific partners. (Gallin,2001).

In the field of trainings, trade unions have generally preferred to work on their own or through labor NGOs. Its national affiliates include specialized education NGOs linked to the labor movement, trade unions (often through their education departments), educational institutions of social-democratic parties, think tanks and research institutes. Although there is not an extensive co-operation between trade unions and non-trade NGOs in the field of education, the individual perceptions on how sensitivity training to develop and foster smart society has mutual areas. As seen in the findings, the main themes were collected under the headings of communication, productivity and respected organization. If there is communication between two creatures in one place, there is a channel for communication, that is, someone who gives the message has positive and negative influencers, a target that receives the message, and the target filters that receive the message. If an effective communication is desired to be established in the workplace, the message that needs to be conveyed should be in a great overlap with what the other party understands. According to the participants' point of view good communication can 
be learned Therefore, it is necessary to have knowledge and practice about how communication can be established and how it should be. In this respect sensitivity training is one of the best methods to establish this phenomenon. Also, the Comparable relations between academic institutions and the trade union movements can be helpful in this respect in fostering of smart society.

On the other hand, further studies could also compare from the gender perspective that is concentrating on for example on the women's rights and equality issues. The relationship between trade union NGOs and the women's movement has been complex and contradictory. The trade union NGOs usually has been dominated by the culture of the male industrial worker" apart from the textile and garment industries. The industrial culture was not friendly to women. In several countries' women had to create their own unions because they were not welcome in the existing trade union movement. Faced with increasing pressure from the women's movement over the last three decades and with the fact that women represent a growing share of the labor force, unions have undertaken serious efforts in many countries to open trade unions to women. In this context, unions have increasingly entered partnerships with women's NGOs, organizing drives and forming alliances to represent informal workers' interests.

In the light of the findings it can be stated also that with sensitivity training in the workplace, social relations and group atmosphere improve. When benefits of sensitivity training is overlooked, it can be stated that with the education of sensitivity, very useful results are reached for individuals, groups and organizations. The benefits that can be obtained from these three aspects can be examined.

In terms of the personal perspective abilities, emotions, and motivations can come forward. During this training, feedback can be provided by colleagues who participated in the training process. The individual will be able to see the effects of his behavior and his behavior on others, and what kind of influence and behavior he has had on the others and will be able to analyze why he perceives these behaviors in different ways. Additionally, may understand the misconceptions of this behavior, and the subject, as a result will be required to act with more understanding and tolerance towards others.

In terms of group perspective, it can be stated that the group came together to achieve a specific purpose. There will be given the opportunity to recognize and learn a team of people who have a place and role in a group that is satisfactory for the self-acceptance of people and the distress. In addition, anyone who undergoes sensitive training will be able to see the group structure, the communication system and the dynamics in the group's behavior. In the sensitivity training of the group, there are also opportunities for making decisions and implementing them on many issues. For this reason, a person who participates in the training also can spend time on how to discuss the problems in the group. On the one hand, in some cases problems such as breaking up and dissolving the internal problems of the group can be encountered.

In terms of organizational perspective, the sensitivity training is an activity to determine the tasks to be carried out in order to achieve certain goals, to determine the personnel to perform this function, to determine the competencies and responsibilities and organizational relations of global citizens in smart societies. Based on this definition, a sensitivity helps to understand how important and complex the problems are in the education, and to analyze these organizational problems in more detail. 


\section{References}

Akcil, U., Altınay, Z., Altinay, F., Dagli, G., Altinay, M. (2018). The role e-transformational leadership intergenerational cooperation for school culture. INTECH.

Aksal Altınay, F. (2015). Are Headmasters Digital Leaders in School Culture? Education and Science, 40 (182), 77-86.

Altınay, F., Altınay, Z. (2018). Women as social entrepreneurship and the use of technology. European Journal of Sustainable Development (2018), 7, 3, 183-190 ISSN: 2239-5938 Doi: 10.14207/ejsd. 2018.v7n3p183

Altinay, F., Dagli, G. and Altinay, Z. (2017). Role of technology and management in tolerance and reconciliation education. International Journal of Methodology, 15(3), 68-72.

Altınay, F., Dagli, G., Altınay, Z. (2018). How MOOCs Support Collaborative and Conflict management in Schools. BRAIN, 9.

Back, K. W. (1973). Beyond words: The story of sensitivity training and the encounter movement. Baltimore: Penguin Books.

Colin Ball and Leith Dunn (1995). Non-Governmental Organizations: Guidelines for Good Policy and Practice, The Commonwealth Foundation, London, p. 8.

Deliza, R., \& Ares, G. (2018). Consumer Perception of Novel Technologies. Food Engineering Series Fruit Preservation, 1-20. doi: 10.1007/978-1-4939-3311-2_1

Denes, M. (1975). The ethos of sensitivity training. Psychotherapy: Theory, Research, and Practice, 16, 387396.

Eagles, M., Wolitzky, DL. (1999). Empathy: A Psychoanalytic Prespective. Empathy: Reconsidered: New directions in Psychotherapy, 2nd edition. Bohart, A.C, Greenberg L.S. (ed.) Washington, D.C.: American Psychiatric Press.

Fox, J. A. (2000). The struggle for accountability: The World Bank, NGOs and grassroots movements. Cambridge, MA: MIT Press.

Gallin, D. ( 1980). "Unions and transnationals: The beginnings of an international response", in The New International Review, Vol. 3, No. 1, New York.

Gallin, D. (2001). Propositions on Trade Unions and Informal Employment in Times of Globalization. Antipode, 33(3), 531-549. doi: 10.1111/1467-8330.00197

Gallin,D.(2001). Trade Unions and NGOs. Retrieved https://www.globalpolicy.org/component/content/article/176/31313.html

Gazi, A.Z. (2016). Internalization of digital citizenship for the future of all levels of education. Education \& Science, 41(186):137-148.

Giardini, A., \& Cayró, E. V. (2017). Daniel Goleman. Barcelona: Salvat.

Goleman, D. (2006). Working with emotional intelligence. New York: Bantam Books.

Guerrero, L., Claret, A., Verbeke, W., Enderli, G., Zakowska-Biemans, S., Vanhonacker, F., ... Hersleth, M. (2010). Perception of traditional food products in six European regions using free word association. Food Quality and Preference, 21, 225-233

Hirai, Y. (2007). Japon Perspektifinden Türkiye'de Sivil Toplumun Yapısı: Sivil Toplum Araştırmaları Çerçevesinde Türk Sivil Toplum Kuruluşlarının Ana Hatları ve Faaliyetleri. Uluslararası Hukuk ve Politika Dergisi, 3 (9), 101-129.

Hulme, D., \& Edwards, M. (1997). NGOs, States and Donors: An Overview. NGOs, States and Donors, $3-$ 22. doi: 10.1007/978-1-349-25253-4_1

Hutnik, N., \& Gregory, J. (2008). Cultural sensitivity training: Description and evaluation of a workshop. Nurse Education Today, 28(2), 171-178. doi: 10.1016/j.nedt.2007.03.012

Hutnik, N., \& Gregory, J. (2008). Cultural sensitivity training: Description and evaluation of a workshop. Nurse Education Today, 28(2), 171-178. doi: 10.1016/j.nedt.2007.03.012

Kajee L (2018). Teacher education students engaging with digital identity narratives. South African Journal of Education, 38(2):1-9.

MacIsaac, D.S. (1999). Empathy: Heinz Kohut's contribution. Empathy: Reconsidered; New directions in Psychotherapy, 2nd edition. Bohart, A.C., Greenbergg, L.S. (ed.). Washington, D.C.: American Psychiatric Press 
Ozansoy,K., Altınay, Z., Altınay, F. (2018). Developing Strategies to Prevent “Cyber-Bullying”, EURASIA J. Math., Sci Tech. Ed 2018;14(5):1925-1929 DOI: 10.29333/ejmste/85499

Poteat T, Park C, Solares D, et al. (2017). Changing hearts and minds: Results from a multicountry gender and sexual diversity training. Newman PA, editor. PLoS One. 12(9): e0184484-e0184516

Şimşek, E. ve Şimşek, A., (2013). New literacies for digital citizenship. Contemporary Educational Technology, 4(2), 126-137.

Sozudogru O, Altinay M, Dagli G, Altinay Z \& Altinay, F. (2019). Examination of connectivist theory in English language learning. International Journal of Information and Learning Technology, 36(4):354-363.

Strauss, A., \& Corbin, J. (1990). Basics of qualitative research. London: Sage.

Timmermans, \& Jourava. (2017). Equality between Women and Men. The EU Charter of Fundamental Rights: A Commentary. doi: 10.5040/9781849468350.ch-026

Williams, J. C. (2005). The glass ceiling and the maternal wall in academia. New Directions for Higher Education, 130. pp. 91-105.

World Labour Report (1997) 1997-1998: Industrial Relations, Democracy and Social Stability, International Labour Organization.

Yıldırım, A., \& Şimşek, H. (2016). Sosyal bilimlerde nitel araş,ırma yöntemleri. Ankara: Seçkin Yayıncılık.

Yin, R., (1984). Case study research. Beverly Hills, CA: Sage Publications 